\title{
Photosynthesis enhancement in maize via nontoxic orange carbon dots
}

Ivana Milenković, Milan Borišev, Yiqun Zhou, Sladjana Z. Spasić, Roger M. Leblanc, Ksenija Radotić

\section{Materials and methods}

Excitation and emission spectra of o-CDs

The fluorescence spectra of the honey samples were recorded using an Fl3-221 P spectrofluorometer (Jobin Yvon, Horiba, France), equipped with a $450 \mathrm{~W}$ Xe lamp and a photomultiplier tube. The sample was measured in $3 \mathrm{~mL}$ quartz cuvette, $10 \mathrm{~mm}$ optical path, placed in a solid sample holder, in the right-angle configuration. The fluorescence emission spectra in the range $540-650 \mathrm{~nm}$ were recorded at the $280 \mathrm{~nm}$ excitation, and the absorbance of the sample was in the $0.06-0.15$ range. The excitation spectrum was recorded in the range $250-$ $350 \mathrm{~nm}$ at the $560 \mathrm{~nm}$ emission. The slit widths were $5 \mathrm{~nm}$ for both excitation and emission. The fluorescence quantum yield was calculated using the FluorEssence V3.5 software incorporated in the spectrofluorometer, as the ratio of the total number of emitted photons and the total number of absorbed photons.

\section{Results}

The excitation and emission spectrum of o-CDs are shown in Figure S1. The emission spectrum had the $560 \mathrm{~nm}$ maximum at $280 \mathrm{~nm}$ excitation. The excitation spectrum had the $280 \mathrm{~nm}$ maximum at $560 \mathrm{~nm}$ emission, and corresponded to the absorption spectrum. The calculated fluorescence quantum yield is $1.02 \%$. 

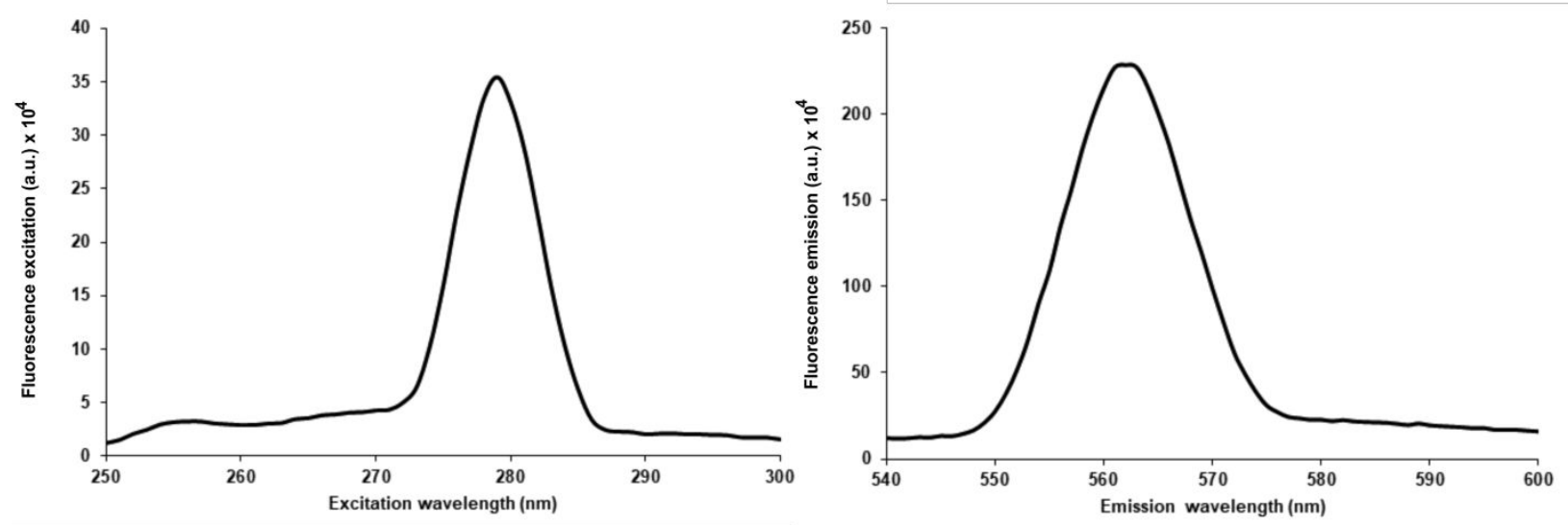

Figure S1. Excitation (left) and emission (right) spectrum of $5 \mathrm{mg} \mathrm{L}^{-1} \mathrm{o}-\mathrm{CDs}$ in water solution. 